Berkala Ilmu Perpustakaan dan Informasi, Vol. 14, No. 2, Desember 2018, Hal. 226-237

DOI: 10.22146/bip.33844

ISSN 1693-7740 (Print), ISSN 2477-0361 (Online)

Tersedia online di https://jurnal.ugm.ac.id/bip

\title{
Pemanfaatan media sosial untuk pencarian dan komunikasi informasi kesehatan
}

\author{
Rosini $^{1}$ dan Siti Nurningsih ${ }^{1}$ \\ ${ }^{1}$ Ilmu Perpustakaan dan Informasi, Fakultas Teknologi Informasi \\ Universitas YARSI \\ Jl. Letjen Suprapto, Cempaka Putih Jakarta 10510 \\ Email:rosini@yarsi.ac.id
}

\section{Naskah diterima: 11 Maret 2018, direvisi: 12 Juli 2018, disetujui: 15 Agustus 2018}

\begin{abstract}
ABSTRAK
Pendahuluan. Penelitian bertujuan untuk mengetahui pemanfaatan media sosial dalam rangka mencari dan mengomunikasikan informasi tentang kesehatan.

Metode Penelitian. Metode penelitian yang digunakan adalah metode kuantitatif dengan jenis survey sedangkan teknik pengumpulan datanya adalah kuesioner. Populasinya adalah pengguna media sosial dengan teknik sampling nonprobability jenis kuota.

Analisis data. Data dianalisis menggunakan statistik deskriptif dengan bantuan SPSS.

Hasil dan pembahasan. Profil pengguna media sosial didominasi oleh wanita, usia 45-50 tahun, rata-rata telah menikah, dan berpendidikan D4/S1. Media sosial yang paling sering digunakan untuk mencari informasi kesehatan yakni Whatsapp (85.8\%), YouTube (84.9\%), Wikipedia (84\%), dan Facebook (80.5\%). Sisanya yakni Blogger (73.4\%), Instagram (64.6\%), Google+ (61\%), dan Wordpress (58.4\%). Alasan penggunaannya "adanya berbagai fasilitas untuk share, memberikan komentar, membalas percakapan, tagging, dan mengunggah foto". Alasan lainnya adalah "Semua teman saya menggunakannya", "Tampilannya nyaman untuk dilihat dan digunakan", dan "Ada notifikasi (pemberitahuan)". Media sosial yang dapat memenuhi alasan tersebut yakni Facebook.

Kesimpulan. Pengguna media sosial untuk pencarian dan komunikasi informasi kesehatan merupakan usia produktif, didominasi perempuan, dan berpendidikan tinggi, menggunakan Personal social networking sites. Pola pemanfaatan media sosial untuk keperluan pencarian dan komunikasi informasi kesehatan yaitu memanfaatkan semua perangkat akses, "sering" menerima informasi kesehatan melalui media sosial tetapi "jarang" mengomunikasikan kembali kepada pengguna lainnya.
\end{abstract}

Kata Kunci: Media Sosial; Informasi Kesehatan; Pencarian Informasi ; Komunikasi Informasi

\section{ABSTRACT}

Introduction. This study aims to determine the utilization of social media based on the framework of health information seeking behavior and information dissemination.

Data collection method. The study used survey with social media users as population by using nonprobabilitysampling.

Analysis data. The survey data was processed by using SPSS program for further descriptive analysis.

Results and discussions. Our results showed that social media users were dominated by female (age range 4550 years old) with "married" as their status. Their highest level of education was D4 (Diploma) and S1 (undergraduate). They used WhatsApp (85.8\%), YouTube (84.9\%), Wikipedia (84\%), Facebook (80.5\%), Blogger (73.4\%), Instagram (64.6\%), Google+ (61\%), and Wordpress (58.4\%). The reasons for seeking health information through media were several facilities such to share, to give comment, to create conversation, to tag topics, and to upload photos. Other reasons were "all of my friends use it", "the display is convenient to use", and "have notifications". 
Conclusions. Our results concludes that patterns of social media use was active seeking information related to health with less sharing information to others.

Keywords: social media; health information; information seeking, information searching

\section{A. PENDAhULUAN}

Kesehatan merupakan hal yang sangat penting, karena sehat merupakan aset bagi seseorang untuk melakukan semua kegiatan sehari-hari. Jika seseorang sakit maka semua aktivitas bisa terhambat bahkan berhenti sama sekali. Oleh karena itu menjaga dan memelihara kesehatan merupakan pilihan yang jauh lebih baik dibandingkan menunggu sampai jatuh sakit. Kesehatan yang baik berasal dari menerima kualitas layanan tentang menghentikan penyakit sebelum dimulai atau melakukan tindakan pencegahan (Winterfeld, 2012). Lebih jauh Winterfeld (2012) menyatakan pencegahan harus dijalin menjadi semua aspek kehidupan kita, termasuk di mana dan bagaimana kita hidup, belajar, bekerja dan bermain. Semua orang - pebisnis, pendidik, institusi perawatan kesehatan, pemerintah, masyarakat dan setiap orang Amerika memiliki peran dalam menciptakan bangsa yang lebih sehat. Kesadaran akan pentingnya menjaga kesehatan ini membuat masyarakat banyak mencari informasi tentang kesehatan.

Seiring dengan berkembangnya teknologi, maka pencarian informasi kesehatan yang tadinya hanya dilakukan pada sumber tercetak atau pada situs kesehatan tertentu, kini berkembang pada media internet. Penggunaan internet telah mengubah hubungan manusia dengan informasi, dan menjadikan "online resources" sebagai sumber informasi kesehatan yang penting di Amerika (Fox, 2011). Bahkan generasi yang lahir setelah era 90-an merupakan generasi yang melek di dunia langsung melihat internet dan piranti teknologi (gadget) sehingga secara popular disebut sebagai "the digital native" (Uswah, 2016). Masih dalam sumber yang sama disebutkan pula bahwa generasi ini terikat dengan gadget dan tidak mempunyai hambatan mengoperasikan peralatan komunikasi serumit apapun, apalagi mengakses teknologi komputer. Salah satu hal yang berkembang di dunia internet yakni media sosial (social media). Beberapa media sosial yang dikenal seperti Facebook, MySpace, YouTube, Twitter, Pinterest, Wikipedia, Linkedin, Reddit, Amazon, Ebay, dsb. (Csordás, Gáti, \& Markos-Kujbus, 2014). Kaplan dan Haenlein (2010) mendefinisikan media sosial sebagai sebuah kelompok aplikasi berbasis internet yang membangun di atas dasar ideologi dan teknologi Web 2.0, dan yang memungkinkan penciptaan dan pertukaran user-generated content.

Seperti halnya di seluruh negara lain, di Indonesia para penguna media sosial juga terus mengalami peningkatan dari tahun ke tahun. Menurut We Are Social (Kemp, S., 2018), sebuah perusahaan yang melakukan kajian pemanfaatan digital sosial dan handphone di seluruh dunia, menyatakan bahwa pengguna internet di Indonesia saat ini berjumlah 132,7 juta orang dari jumlah tersebut, 130 juta orang menggunakan media sosial secara aktif.

Besarnya akses terhadap internet dan media sosial ini, bahkan mengalahkan akses masyarakat Indonesia terhadap kegiatan "menonton" yang rata-rata hanya selama 2 jam 45 menit perhari dibandingkan dengan pengguna internet yang mengakses internet selama 8 jam 51 menit per hari dan menggunakan media sosial selama 3 jam 23 menit tiap harinya.

Oleh karena itu dapat dilihat bahwa saat ini media sosial menjadi pilihan masyarakat untuk berkomunikasi. Salah satu komunikasi dengan menggunakan media sosial yakni mengenai informasi kesehatan. Namun demikian, perlu dilakukan penelitian lebih lanjut efektivitas pemanfaatan media sosial dalam pencarian dan komunikasi informasi kesehatan.

Berdasarkan latar belakang tersebut, maka tujuan penelitian ini: menganalisis profil pengguna media sosial yang memanfaatkan media sosial untuk mencari dan mengomunikasikan informasi kesehatan, 
menganalisis media sosial yang paling banyak digunakan untuk mencari dan mengomunikasikan informasi kesehatan. Kajian ini juga bertujuan menganalisis alasan penggunaan media sosial dalam mencari dan mengomunikasikan informasi kesehatan. Selain itu penelitian juga menganalisis pola pemanfaatan media sosial dalam pencarian dan mengomunikasikan informasi kesehatan.

Sebuah penelitian yang dilakukan oleh Kim dan Syn (2016), meneliti persepsi mahasiswa terhadap kredibilitas dan kegunaan informasi kesehatan di Facebook berdasarkan faktor topik, sumber informasi dan demografi. Dengan menggunakan metode sampling selektif terhadap 351 responden yang berasal dari 2 universitas. Hasilnya menunjukkan bahwa (1) para mahasiswa cenderung menganggap topik informasi kesehatan dengan tingkat sensitivitas rendah secara signifikan lebih dapat dipercaya dan bermanfaat daripada topik informasi kesehatan dengan tingkat sensitivitas tinggi pada Facebook. (2) Mahasiswa cenderung menganggap sumber informasi profesional lebih dipercaya dan bermanfaat daripada sumber informasi non-profesional pada Facebook. Namun, di antara sumber informasi non-profesional, (3) para mahasiswa lebih memilih orang berpengalaman daripada keluarga jika menyangkut masalah kesehatan yang serius. (4) Mahasiswa berjenis kelamin perempuan cenderung mempercayai informasi kesehatan yang sangat sensitif lebih banyak dibandingkan mahasiswa laki-laki. (5) Mahasiswa yang tinggal di asrama cenderung tidak mempertimbangkan informasi kesehatan pada Facebook sebagai sumber informasi yang dapat dipercaya. Semakin terdidik mahasiswa, semakin besar tingkat kepercayaan mereka terhadap sumber informasi yang profesional.

Penelitian yang dilakukan penulis berbeda dengan penelitian Kim dan Syn (2016). Pada penelitian ini, media sosial yang digunakan untuk mencari informasi kesehatan belum ditentukan di awal, jadi semua kemungkinan media sosial yang digunakan untuk mencari informasi kesehatan dimasukan ke dalam penelitian ini untuk dilihat mana yang digunakan untuk mencari dan mengomunikasikan informasi kesehatan. Selain itu, responden yang digunakan dalam penelitian ini tidak hanya mahasiswa pada sebuah universitas, akan tetapi dari berbagai kalangan masyarakat yang berusia di atas 18 tahun atau sudah dianggap dewasa. Dengan responden dan media sosial yang berbeda, meskipun menggunakan analisis yang sama, maka hasilnya dapat berbeda.

\section{B. TINJAUAN PUSTAKA \\ 1. Media Sosial}

Media Sosial terus menerus mengalami perkembangan dari masa ke masa baik dalam segi kuantitas maupun kualitas. Miller et al. (2015) menyampaikan sejarah media sosial kemungkinan berawal di Korea dengan suksesnya Cyworld, platform yang diluncurkan pada tahun 1999 dan menjadi aplikasi pertama yang dapat menjangkau secara efektif anakanak muda dari sebuah populasi yang signifikan. Cyworld menjadi popular pada tahun 2005 dimana hampir semua anak muda di Korea menggunakan Cyworld. Salah satu karakteristik Cyworld adalah dapat mengoperasikan kategori pertemanan sebagai sebuah lingkaran yang terpusat. Para akademisi kemudian menyimpulkan bahwa sistem kerja Cyworld hampir sama dengan sistem kekerabatan cara tradisional yang ada di Korea. Hal ini merupakan salah satu kemungkinan yang membuat Cyworld sangat sukses di Korea tapi tidak digunakan di negara lain. Akhirnya Cyworld pun digantikan oleh Facebook (Miller et al., 2015). Pada tahun yang sama, QQ di China juga diluncurkan yang awalnya adalah sebuah layanan pesan singkat (SMS). Selain itu ada juga Frends Reunited yang muncul pada tahun yang sama.

Friendster digunakan di Amerika mulai tahun 2002, meskipun demikian lebih berkembang di Asia Tenggara, bahkan akhirnya dibeli oleh perusahaan pebisnis Malaysia (Miller et al., 2015). Sama halnya dengan Orkut yang diluncurkan oleh Google yang popular di Brazil dan India. Pada tahun 2003, MySpace diluncurkan di Amerika Utara. Setahun keemudian, MySpace popular di kalangan remaja di Amerika Utara. Selain MySpace, pada 
tahun yang sama, yaitu tahun 2003, LinkedIn juga diluncurkan. Kemudian secara berturutturut lahir Facebook tahun 2004, Twitter tahun 2006, Wiser tahun 2007, WhatsApp tahun 2009, Instagram tahun 2010, Snapchat, WeChat, dan Google+ tahun 2011. Saat ini Facebook merupakan aplikasi yang paling banyak digunakan di seluruh dunia, diikuti oleh Whatsapp Messanger, WeChat, dan Facebook Messanger (Kemp, 2018).

Begitu banyak aplikasi media sosial dengan berbagai platform, membuat Csordás et al., (2014) mengelompokan media sosial menjadi 8 kelompok seperti yang ditampilkan pada Gambar 1.

Masing-masing media sosial, mempunyai tujuan yang berbeda dengan lainnya misalnya "business networking sites" seperti LinkedIn digunakan untuk memelihara hubungan formal seseorang, sementara "blogs" digunakan oleh perusahaan untuk tujuan promosi perusahaan tersebut (Csordás et al., 2014).

Kietzmann, Hermkens, McCarthy, \& Silvestre (2011) menyatakan ada 7 "functional block" dalam media sosial yang memberikan kontribusi untuk mengerti bagaimana mekanisme sebuah media sosial bekerja, yaitu: (1) identity, yang menggambarkan bagaimana konsumen mengungkapkan diri mereka di platform media sosial. (2) conversations, adalah cara komunikasi konsumen, termasuk motivasi, frekuensi, dan konten. (3) presence, ditentukan oleh bentuk media. Dalam hal ini, komunikasi dapat bersifat interpersonal (misalnya diskusi tatap muka) atau dimediasi (misalnya Percakapan telepon). Dengan kedekatan media, seseorang dapat membedakan komunikasi asinkron (misalnya Email) dan sinkron (misalnya obrolan langsung). (4) groups, adalah komunitas atau sub-komunitas, yang merupakan elemen bangunan media sosial. Terdapat dua jenis grup utama, yaitu yang terbuka untuk siapa saja (misalnya, tanggapan blog, papan pesan), sedangkan kelompok jenis pengguna lainnya adalah yang memungkinkan pengguna untuk mengelola hubungan mereka sendiri dan membuat grup dari mereka (misalnya Situs jejaring sosial). relationships, menguraikan hubungan antara peserta suatu komunitas. Modus koneksi pengguna sering menentukan "apa dan bagaimana pertukaran informasi". Ada hubungan yang kuat antara identitas dan hubungan: Semakin tinggi identitas dihargai oleh komunitas media sosial, semakin tinggi hubungan dihargai. (6) reputation, adalah ukuran konsumen - mengidentifikasi diri mereka sendiri, terutama yang berkaitan dengan orang lain di masyarakat. Ada beberapa metrik sehubungan dengan blok ini: kekuatan, sentimen, semangat, dan jangkauan. (7) sharing, berkaitan dengan proses pertukaran konten antara pelaku yang berpartisipasi berbeda. Ada dua implikasi mendasar untuk komunikasi perusahaan sehubungan dengan kemauan pengguna untuk berbagi. Pertama, objek pembagian pengguna dan kedua, kecenderungan mereka untuk berbagi.

Dari 7 fungsi tersebut, maka Kaplan and Haenlein dan Weinberg and Pehlivan (dalam Csordás et al., 2014) membuat klasifikasi media sosial dalam implikasinya terhadap perusahaan seperti pada Tabel 1.

Salah satu penelitian yang melakukan kajian implikasi media sosial terhadap perusahaan nonkomersial dilakukan oleh Siswanti (2016). Siswanti mengkaji peran salah satu media sosial, yaitu Facebook, dalam hal layanan peminjaman di perpustakaan. Dalam penelitian ini Siswanti menyimpulkan terdapat pengaruh positif pada layanan perpanjangan masa peminjaman koleksi dengan menggunakan media sosial Facebook (Siswanti, 2015).

\section{Media Sosial untuk pencarian, komunikasi dan penyebaran informasi kesehatan}

Beragamnya jenis media sosial dengan berbagai kelebihan dan kekurangannya serta penggunaan media sosial yang terus menerus mengalami peningkatan setiap tahunnya, membuat para peneliti melakukan berbagai kajian yang terkait dengan fenomena ini. Berbagai penelitian mengenai pemanfaatan media sosial banyak dilakukan antara lain di bidang marketing dan kesehatan. Bahkan Zhao \& Zhang (2017) dari School of Information Studies, University of Wisconsin-Milwaukee, 
Milwaukee, WI, USA melakukan penelitian yang bertujuan untuk membuat ringkasan penelitian mengenai bagaimana konsumen mencari informasi yang berhubungan dengan kesehatan dari media sosial. Dengan harapan mengungkapkan karakteristik penelitian yang sudah ada yang mengkaji topik kesehatan yang telah dibahas konsumen di media sosial, memastikan peran yang dimainkan media sosial dalam proses pencarian informasi konsumen dan mendiskusikan potensi keuntungan dan kekhawatiran mengakses informasi kesehatan konsumen di media sosial. Hasil penelitian ini adalah: antara tahun 2011 dan 2016, terdapat 21 kajian yang diterbitkan yang mengeksplorasi berbagai topik yang terkait dengan pencarian informasi kesehatan oleh para konsumen di media sosial. Ini berkisar dari diskusi online tentang penyakit tertentu (misalnya Diabetes) hingga masalah kesehatan masyarakat (misalnya residu pestisida). Kebutuhan informasi konsumen bervariasi tergantung pada masalah-masalah kesehatan yang diminati. Manfaat mencari kesehatan di media sosial, selain mengisi informasi mengenai informasi kesehatan, para konsumen kesehatan juga mengharapkan untuk mendapatkan dukungan sosial dan emosional dari interaksi antar teman. Namun, dikhawatirkan juga kualitas informasi dan otoritas yang pada akhirnya mengarah pada penurunan keterlibatan konsumen.

Beberapa penelitian yang terkait dengan informasi kesehatan dan media sosial antara lain yakni:

a. Informasi kesehatan dengan sosial media

Oh \& Kim (2014) melakukan sebuah penelitian eksplorasi yang bertujuan untuk memahami penggunaan dan persepsi mahasiswa terhadap media sosial untuk informasi kesehatan dengan membandingkan mahasiswa di Amerika Serikat dan Korea. Penelitian yang dilakukan pada mahasiswa di 2 negara dengan alasan baik Amerika maupun Korea merupakan negara terdepan dalam hal pengembangan internet dan media sosial, sehingga mahasiswa diperkirakan mempunyai pengalaman terhadap informasi kesehatan pada media sosial (Oh \& Kim,
2014). Alasan lainnya untuk melihat perbedaan pemanfaatan media sosial untuk informasi kesehatan di kedua negara tersebut, karena kedua negara tersebut mempunyai norma sosial yang berbeda dalam memanfaatkan informasi kesehatan yang dicari atau diperoleh dari berbagai sumber online. Hasil penelitian menunjukkan mahasiswa Amerika lebih aktif menggunakan dan berinteraksi mengenai perawatan kesehatan pada media sosial dibandingkan mahasiswa Korea. Hasil penelitian Oh \& Kim lainnya mengungkapkan 5 jenis media sosial yang paling banyak digunakan, Social $Q \& A s$, Social networking sites, Blogs, Podcasts, Twitter. Kelima media sosial ini bisa dijadikan pertimbangan sebagai saluran untuk informasi kesehatan di kalangan mahasiswa di Amerika dan Korea.

Sebuah penelitian lainnya dilakukan oleh Chou, Hunt, Beckjord, Moser, \& Hesse (2009) yang bertujuan mengidentifikasi faktor sosio demografi dan kesehatan yang dihubungkan dengan pengguna media sosial pada orang dewasa di Amerika. Hasilnya sekitar $69 \%$ orang dewasa AS melaporkan memiliki akses ke internet. Di antara pengguna internet tersebut, $5 \%$ berpartisipasi dalam kelompok online, $7 \%$ menggunakan blogging, dan $23 \%$ menggunakan situs jejaring sosial. Kesimpulan penelitian ini menunjukkan pertumbuhan media sosial tidak terdistribusi secara merata di seluruh kelompok usia, oleh karena itu, program komunikasi kesehatan yang menggunakan media sosial harus terlebih dahulu mempertimbangkan usia populasi yang ditargetkan untuk membantu memastikan bahwa pesan mencapai audiens yang dituju. Temuan ini menunjukkan bahwa teknologi baru, yang diwakili oleh media sosial, dapat mengubah pola komunikasi di seluruh Amerika Serikat.

Penelitian yang mengkaji media sosial dalam komunikasi kesehatan dilakukan oleh Habibi, Farpour, \& Pirzad (2017). Kesimpulan penelitian ini adalah media sosial harus menjadi bagian dari sebuah 
program sistem kesehatan yang diberikan kepada orang-orang melalui informasi yang dibutuhkan. Selain itu media sosial dapat digunakan untuk membuat hubungan sosial antara kelompok dengan karakteristik umum dan mengurangi stres yang disebabkan oleh penyakit kronis dan perubahan perilaku pasien.

b. Informasi kesehatan dengan jenis media tertentu

Selain penelitian yang mengkaji pemanfaatan media sosial secara umum yang terkait dengan informasi kesehatan, ada juga beberapa penelitian yang mengkhususkan pada jenis media sosial tertentu, yaitu antara lain sebagai berikut:

Penelitian yang dilakukan oleh Zhang (2013) dari The University of Texas at Austin, School of Information, Austin, Texas, USA. Kajian Yan Zhang ini mengeksplorasi penggunaan situs jejaring sosial untuk informasi kesehatan dan kesejahteraan oleh mahasiswa serta untuk mengetahui persepsi mereka tentang penggunaan media sosial tersebut. Hasil penelitian diperoleh bahwa, mahasiswa yang memiliki pengalaman menggunakan jejaring sosial untuk informasi kesehatan menggunakan platform ini untuk mengetahui update kesehatan orang-orang yang dicintainya, menemukan informasi tentang gaya hidup dan menanyakan cara perawatan untuk kondisi kesehatan ringan. Secara keseluruhan partisipan bersikap skeptik terhadap kualitas informasi, merasa prihatin dengan kurangnya pengetahuan teman atau rekan mereka, dan khawatir tentang kemungkinan resiko sosial dan invasi terhadap "privacy" mereka. Berdasarkan hasil tersebut, selain mendiskusikan implikasi untuk mendesain platform sosial media yang dapat mendukung kebutuhan informasi kesehatan, hasil lainnya adalah sebuah model penerimaan pengguna terhadap situs jejaring sosial untuk informasi kesehatan dan kesejahteraan berhasil dikemukakan. Model tersebut dapat dilihat pada Gambar 2.
Pada akhir penelitian tersebut, disimpulkan bahwa pemanfaatan situs jejaring sosial untuk informasi kesehatan dan kesejahteraan bukan perilaku yang popular di kalangan mahasiswa dan situs jejaring sosial bukan platform yang diterima dengan baik untuk informasi kesehatan dan kesejahteraan.

Sebuah penelitian lainnya yang mengkhususkan untuk meneliti salah satu media sosial yang popular di Indonesia, yaitu Facebook dilakukan oleh Kim \& Syn (2016). Penelitian ini mengkaji faktor-faktor yang mempengaruhi mahasiswa untuk melakukan pencarian (seeking) dan penyebaran (sharing) informasi kesehatan pada Facebook. Terdapat dua faktor, yaitu Faktor kontekstual, seperti topik kesehatan yang sensitif, dan sumber informasi kesehatan. Faktor lainnya adalah faktor pengguna, seperti faktor demografi. Hasil penelitian ditemukan bahwa mahasiswa bersedia membaca dan membagikan lagi informasi kesehatan di Facebook jika topik kesehatan nya bukan topik kesehatan yang sensitif. Selain itu, ada perbedaan yang jelas dalam preferensi antara sumber profesional dan sumber pribadi sebagai sumber informasi kesehatan. Ditemukan pula bahwa sebagian besar faktor pengguna, kecuali jenis kelamin, tidak memiliki pengaruh pada aktivitas informasi kesehatan.

\section{METODE PENELITIAN}

Jenis penelitian yang digunakan adalah penelitian survey dengan metode penelitian kuantitatif. Kuesioner sebagai teknik pegumpulan data disebarkan melalui 2 platform media sosial yaitu Faceboook dan Whatsapp group, dan email berupa link untuk mengisi kuesioner online pada Google form. Sebelum disebarkan terlebih dahulu dilakukan uji validitas dan reliabilitas pada kuesioner. Subjek penelitian ini yakni para pengguna media sosial. Sedangkan objek penelitiannya adalah perilaku pencarian dan komunikasi informasi kesehatan. Sehingga variabel yang diamati adalah perilaku 
pencarian dan komunikasi informasi kesehatan para pengguna media sosial. Populasi dari penelitian ini adalah para pengguna media sosial yang dewasa atau di atas usia 18 tahun. Data yang dihasilkan dari kuesioner dianalisis secara deskriptif dengan berbagai perhitungan menggunakan bantuan SPSS.

\section{HASIL DAN PEMBAHASAN}

\section{Profil Pengguna Media Sosial}

Dari hasil pengumpulan data kuesioner dapat digambarkan profil para partisipan atau responden, yaitu dari segi usia, jenis kelamin, status pernikahan, dan jenjang pendidikan.

a. Usia

Pengguna media sosial yang melakukan pencarian dan mengomunikasikan informasi kesehatan tersebar di seluruh kelompok usia. Akan tetapi kelompok usia yang paling banyak adalah kelompok 45 49 tahun dengan 21\%. Urutan kedua kelompok usia $20-24$ tahun dengan jumlah $19.3 \%$. Dua kelompok besar lainnya adalah kelompok usia 15 - 19 tahun sebesar $15.1 \%$, dan kelompok usia 30 - 34 tahun sebesar $14.3 \%$. Jika dilihat, maka golongan usia yang menggunakan media sosial berada pada golongan usia produktif, yaitu lebih dari 15 tahun dan kurang dari 60 tahun

b. Jenis Kelamin dan Status Pernikahan

Untuk jenis kelamin didominasi oleh perempuan dengan jumlah sebesar $76.3 \%$, sedangkan laki-laki nya hanya $23.5 \%$. Para responden juga rata-rata sudah menikah dengan jumlah $55.5 \%$. Sisanya sebesar $42.9 \%$ belum menikah dan hanya $1.7 \%$ yang berstatus janda/duda.

c. Jenjang Pendidikan

Untuk jenjang pendidikan rata-rata para pengguna media sosial berpendidikan S1 atau D4 (52,1\%). Diikuti oleh pendidikan S2 dengan jumlah 29 orang $(24,4 \%)$. Diurutan selanjutnya dengan jumlah persentase yang sama yaitu $11.8 \%$, responden berpendidikan SMA sederajat dan D1/D2/D3.

\section{Media sosial yang paling banyak digunakan}

Dari penelitian ini terdapat delapan media sosial yang paling sering digunakan, yaitu Whatsapp $(85.8 \%)$, YouTube $(84.9 \%)$, Wikipedia (84\%), dan Facebook (80.5\%). Sisanya adalah Blogger (73.4\%), Instagram (64.6\%), Google+ (61\%), dan Wordpress (58.4\%). Hasil penelitian ini sedikit berbeda dengan laporan dari Kemp (2018) yang menyebutkan urutan 4 platform media sosial yang paling aktif, yaitu YouTube, Facebook, Whatsapp, dan Instagram. Sedangkan untuk kelompok media sosial, menurut Kaplan \& Haenlein (2010) dan Csordás, Markos-Kujbus, \& Gáti (2014) YouTube merupakan sosial media yang masuk ke dalam kategori Content communities dengan jenis media sharing. Whatsapp tidak ada pada 2 sumber tersebut, akan tetapi berdasarkan definisinya dan pengelompokannya, Whatsapp bisa masuk ke dalam Personal social networking sites, sama halnya dengan Facebook. Sedangkan untuk Wikipedia masuk ke dalam kelompok collaborative projects.

\section{Alasan penggunaan media sosial}

Berbagai alasan mengapa menggunakan media sosial untuk mencari informasi kesehatan dapat dilihat pada Tabel 2.

Dari Tabel 2. dapat diketahui alasan pengunaan media sosial untuk mencari dan mengomunikasikan iformasi kesehatan disebabkan (1) Ada berbagai fasilitas untuk share, memberikan komentar, membalas percakapan, tagging, dan unggah foto sebesar $62 \%$. Alasan lainnya adalah (2) Semua teman menggunakannya sebesar $56 \%$, (3) adanya berbagai fasilitas yang memudahkan pencarian informasi kesehatan, dan (4) Tampilannya nyaman untuk dilihat dan digunakan serta Ada notifikasi (pemberitahuan), masing-masing $52 \%$. Media sosial dengan alasan tersebut banyak dipilih oleh para pengguna Facebook (49.6\%), kemudian diikuti oleh Instagram dan Whatsapp (18.6\%), dan YouTube (6.19\%). 


\section{Pola Pemanfaatan Media Sosial}

Pencarian dan komunikasi informasi kesehatan, beberapa pola yang tertangkap adalah sebagai berikut:

(1) Perangkat yang digunakan untuk mengakses media sosial.

Para responden mengakses media sosial dengan menggunakan handphone milik sendiri sekaligus menggunakan perangkat komputer yang ada di rumah (38.9\%). Diikuti dengan hanya menggunakan handphone milik sendiri sebesar $21.2 \%$. Setelah itu masing-masing sebesar $17.7 \%$ mengakses media sosial melalui handphone dan komputer di kantor. Mengakses media sosial melalui handphone dan melalui komputer baik di kantor maupun di rumah.

(2) Frekuensi menerima informasi kesehatan pada media sosial

Dapat dikatakan bahwa informasi kesehatan berada pada tingkatan "sering" diterima sebanyak 44 orang atau sebesar 38.9\%. Dapat dilihat pada Tabel 3.

(3) Tindakan para partisipan setelah menerima informasi kesehatan pada media sosial

Setelah menerima informasi kesehatan, ratarata para responden "jarang" memberikan komentar (67 orang), memberikan respon berupa gambar emoticon/stiker atau sejenisnya, dan meneruskan kembali (share, forward). Sisanya berada pada level "cukup sering" memberikan tanda "like" atau sejenisnya yang menyatakan menyukai informasi yang disampaikan. Dapat dilihat pada Tabel 4.

\section{E. KESIMPULAN}

Media sosial yang dapat digunakan untuk keperluan pencarian dan komunikasi informasi kesehatan adalah Whatsapp, Facebook, dan YouTube dengan memanfaatkan HP maupun PC di rumah sebagai perangkat akses. Para pengguna juga "sering" menerima informasi kesehatan melalui media sosial akan tetapi "jarang" mengomunikasikan kembali informasi kesehatan yang diterima kepada pengguna lainnya.
Saran untuk penelitian lain atau lanjutan yang menggunakan media sosial dalam rangka mencari dan mengomunikasikan informasi kesehatan adalah dengan melakukan penelitian terhadap jenis-jenis media sosial tertentu secara terperinci dan detail sehingga dapat disimpulkan bahwa jenis media sosial tertentu bisa digunakan untuk mencari dan mengomunikasikan informasi kesehatan atau tidak. Selain itu dapat diteliti pula, pemanfaatan media sosial untuk penyebaran, pencarian, dan pengkomunikasian topik-topik strategis lainnya selain bidang kesehatan. Sehingga dapat diharapkan pemanfaatan media sosial di Indonesia pada umumnya digunakan untuk halhal yang positif, bukan hal-hal yang destruktif seperti penyebaran berita "hoax", penyebaran berita "kebencian", dan sebagainya.

Ucapan terima kasih kepada Ristek DIKTI yang telah mendanai penelitian ini melalui hibah Penelitian Dosen Pemula tahun 2017. Terima kasih pula untuk para responden yang telah bersedia mengisi kuesioner kami.

\section{DAFTAR PUSTAKA}

Chou, W. S., Hunt, Y. M., Beckjord, E. B., Moser, R. P., \& Hesse, B. W. (2009). Social media use in the United States: Implications for health communication. Journal of Medical Internet Research, 11(4), e48. https://doi.org/10.2196/jmir.1249

Csordás, T., Gáti, M., \& Markos-Kujbus, E. (2014). The attributes of social media as a strategic marketing communication tool. Journalism and Mass Communication Quarterly, 4(1), 48-71.

Fox, S. (2011). The Social Life of Health Information, 2011. Pew Internet \& American Life Project, 1-33. Retrieved May 30, 2016, from http://www.pewinternet.org/ files/old-media/Files/Reports/2011/ PIP_Social_Life_of_Health_Info.pdf.

Habibi, L., Farpour, $\bar{H} . \bar{R}$., \& Pirzad, R. (2017). How does social media affect health communication? International Journal of Brain and Cognitive Sciences, 6(4), 74-79. https://doi.org/doi:10.5923/j.ijbcs.2017060 4.03 
Kaplan, A. M., \& Haenlein, M. (2010). Users of the world, unite! The challenges and opportunities of Social Media. Business Horizons, 53 ( 1), 59-68. https://doi.org/10.1016/j.bushor.2009.09.00 3

Kemp, S. (2018). Digital in 2018: World's internet users pass the 4 billion mark - We Are Social. Retrieved July 31, 2018, from https://wearesocial.com/blog/2018/01/glob al-digital-report-2018

Kietzmann, J. H., Hermkens, K., McCarthy, I. P., \& Silvestre, B. S. (2011). Social media? Get serious! Understanding the functional building blocks of social media. Business Horizons, 54 (3), 241-251. https://doi.org/10.1016/J.BUSHOR.2011.0 1.005

Kim, S. U., \& Syn, S. Y. (2016). Credibility and usefulness of health information on Facebook: A survey study with U.S. college students. Information Research, 21(4). $\mathrm{R}$ e $\mathrm{tr}$ i e ved from ht $\mathrm{p}: / /$ w w w. informationr.net/ir/214/paper727.html

Miller, D., Costa, E., Haynes, N., McDonald, T., Nicolescu, R., Sinanan, J., ... Wang, X. (2015). How The World Changed Social Media. Why we post. UCL Press: London, UK. DOI: 10.14324/111.9781910634493

Oh, S., \& Kim, S. (2014). College students' use of social media for health in the USA and Korea . Information Research, 19(4). $\mathrm{R}$ e t r i e ved from ht t $\mathrm{p}: / /$ www.information r. net/ir/194/paper643.html\#.W1_csj19i01
Siswanti, A. (2015). Pemanfaatan layanan perpanjangan masa peminjaman koleksi melalui media sosial Facebook di Perpustakaan Fakultas Ilmu Sosial dan Ilmu Politik Universitas Gadjah Mada Yogyakarta. Berkala Ilmu Perpustakaan Dan Informasi, 11(2), 1-7. https://doi.org/ 10.22146/bip.10026

Uswah, L. K. (2016). Konsumsi gadget siswa Sekolah Dasar Muhammadiyah Kota Yogyakarta. Berkala Ilmu Perpustakaan dan Informasi, $10(2), 24-32$. https://doi.org/10.22146/BIP.8832

Winterfeld, A. (2012). National prevention strategy. NCSL Legisbrief, 20(28), 1-2. https://doi.org/10.4278/ajhp.26.1.iv

Zhang, Y. (2013). College students' uses and perceptions of social networking sites for health and wellness information. Information Research, 17(3). Retrieved from http://www.informationr.net/ir/173/paper523.html\#.W1_eSz19i00

Zhao, Y., \& Zhang, J. (2017). Consumer health information seeking in social media: A literature review. Health Information \& Libraries Journal, 34(4), 268-283. https://doi.org/10.1111/hir.12192 


\section{DAFTAR GAMBAR}

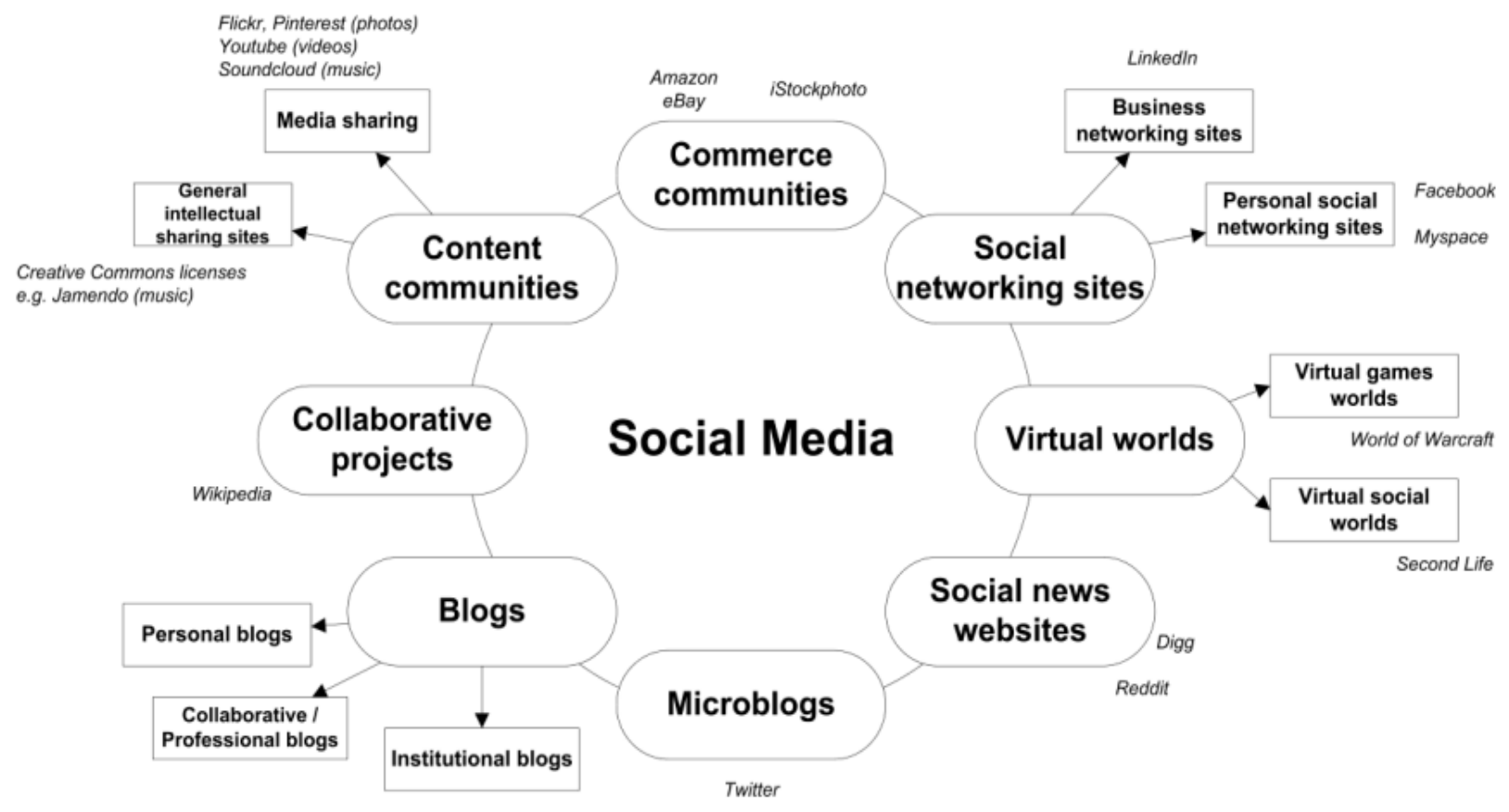

Gambar 1. Pengelompokan Media Sosial

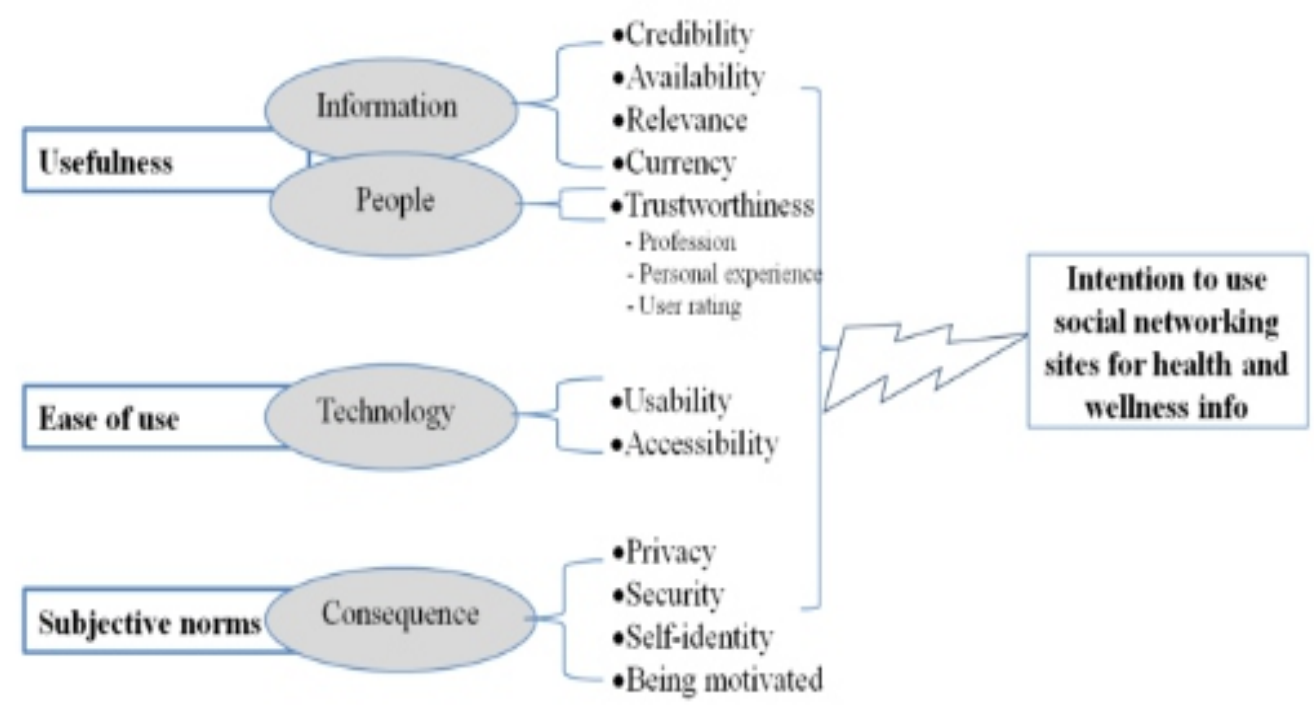

Gambar 2. A model of users' acceptance of social networking sites for health and wellness information Sumber : (Zhang, 2013) 


\section{DAFTAR TABEL}

Tabel 1. Klasifikasi media sosial berdasarkan implikasinya terhadap perusahaan

\section{Corporate Implications of a Possible SM Classification}

\begin{tabular}{|c|c|c|c|c|c|c|c|}
\hline & Blogs & Microblogs & $\begin{array}{l}\text { Social } \\
\text { networks }\end{array}$ & $\begin{array}{l}\text { (Content) } \\
\text { communities }\end{array}$ & $\begin{array}{l}\text { Collaborative } \\
\text { projects }\end{array}$ & $\begin{array}{l}\text { Virtual } \\
\text { social worlds }\end{array}$ & $\begin{array}{l}\text { Virtual } \\
\text { game worlds }\end{array}$ \\
\hline Social presence & low & low & medium & medium & low & high & high \\
\hline Media richness & high & high & high & very high & low & low & low \\
\hline $\begin{array}{l}\text { Self-presentation/ } \\
\text { self-disclosure }\end{array}$ & high & variable & high & low & low & high & low \\
\hline $\begin{array}{l}\text { Half-life } \\
\text { of information }\end{array}$ & long & short & long & long & long & long & short \\
\hline Information depth & shallow & shallow & shallow & deep & deep & shallow & shallow \\
\hline $\begin{array}{l}\text { Examples of } \\
\text { implications for } \\
\text { companies }\end{array}$ & $\begin{array}{l}\text { building } \\
\text { relationships }\end{array}$ & $\begin{array}{l}\text { sales } \\
\text { promotion } \\
\text { programs }\end{array}$ & $\begin{array}{l}\text { building and } \\
\text { maintaining } \\
\text { relationships; } \\
\text { branding }\end{array}$ & $\begin{array}{l}\text { engaging with } \\
\text { content (company } \\
\text { as media content } \\
\text { producer) }\end{array}$ & $\begin{array}{l}\text { co-creation; } \\
\text { crowdsourcing; } \\
\text { user-led } \\
\text { innovation }\end{array}$ & $\begin{array}{l}\text { product } \\
\text { placement }\end{array}$ & $\begin{array}{l}\text { product } \\
\text { placement }\end{array}$ \\
\hline
\end{tabular}

Tabel 2. Alasan penggunaan media sosial untuk pencarian dan komunikasi informasi kesehatan

\begin{tabular}{|c|c|c|c|c|c|c|c|c|c|c|}
\hline \multirow[b]{2}{*}{$\begin{array}{c}\text { Alasan penggunaan media sosial } \\
\text { (Pilihan bisa lebih dari } 1, \\
\text { sehingga prosentase tidak } \\
\text { mencapai 100) }\end{array}$} & \multicolumn{2}{|c|}{ Facebook } & \multicolumn{2}{|c|}{ Google+ } & \multicolumn{2}{|c|}{ Instagram } & \multicolumn{2}{|c|}{ Youtube } & \multicolumn{2}{|c|}{ Whatsapp } \\
\hline & $\begin{array}{c}\text { Fre- } \\
\text { kuen } \\
- \\
\text { si } \\
(n= \\
113)\end{array}$ & $\%$ & $\begin{array}{c}\text { Fre- } \\
\text { kuen } \\
- \\
\text { si } \\
(\mathrm{n}= \\
113)\end{array}$ & $\%$ & $\begin{array}{c}\text { Fre- } \\
\text { kuen } \\
- \\
\text { si } \\
(n= \\
113)\end{array}$ & $\%$ & $\begin{array}{c}\text { Fre- } \\
\text { kuen } \\
- \\
\text { si } \\
(n= \\
113)\end{array}$ & $\%$ & $\begin{array}{c}\text { Fre- } \\
\text { kuen } \\
- \\
\text { si } \\
(n= \\
113)\end{array}$ & $\%$ \\
\hline $\begin{array}{l}\text { Informasi yang disediakan cukup } \\
\text { banyak }\end{array}$ & 46 & $\begin{array}{l}40.7 \\
\%\end{array}$ & 15 & $\begin{array}{c}13.3 \\
\%\end{array}$ & 18 & $\begin{array}{c}15.9 \\
\%\end{array}$ & 12 & $\begin{array}{c}10.6 \\
\%\end{array}$ & 10 & $8.8 \%$ \\
\hline $\begin{array}{l}\text { Memperoleh informasinya lebih } \\
\text { cepat }\end{array}$ & 40 & $\begin{array}{c}35.4 \\
\%\end{array}$ & 12 & $\begin{array}{c}10.6 \\
\%\end{array}$ & 18 & $\begin{array}{c}15.9 \\
\%\end{array}$ & 14 & $\begin{array}{c}12.4 \\
\%\end{array}$ & 20 & $\begin{array}{c}17.7 \\
\%\end{array}$ \\
\hline Mudah menggunakan aplikasinya & 40 & $\begin{array}{c}35.4 \\
\%\end{array}$ & 12 & $\begin{array}{c}10.6 \\
\%\end{array}$ & 18 & $\begin{array}{c}15.9 \\
\%\end{array}$ & 14 & $\begin{array}{c}12.4 \\
\%\end{array}$ & 20 & $\begin{array}{c}17.7 \\
\%\end{array}$ \\
\hline $\begin{array}{l}\text { Mudah mengakses dengan mobile } \\
\text { HP }\end{array}$ & 40 & $\begin{array}{c}35.4 \\
\%\end{array}$ & 13 & $\begin{array}{c}11.5 \\
\%\end{array}$ & 18 & $\begin{array}{c}15.9 \\
\%\end{array}$ & 14 & $\begin{array}{c}12.4 \\
\%\end{array}$ & 23 & $\begin{array}{c}20.4 \\
\%\end{array}$ \\
\hline Ada notifikasi (pemberitahuan) & 52 & $46 \%$ & 13 & $\begin{array}{c}11.5 \\
\%\end{array}$ & 13 & $\begin{array}{c}11.5 \\
\%\end{array}$ & 11 & $9.7 \%$ & 22 & $\begin{array}{c}19.5 \\
\%\end{array}$ \\
\hline $\begin{array}{l}\text { Ada berbagai fasilitas yang } \\
\text { memudahkan pencarian informasi }\end{array}$ & 48 & $\begin{array}{c}42.5 \\
\%\end{array}$ & 15 & $\begin{array}{c}13.3 \\
\%\end{array}$ & 17 & $15 \%$ & 15 & $\begin{array}{c}13.3 \\
\%\end{array}$ & 7 & $6.2 \%$ \\
\hline $\begin{array}{l}\text { Ada berbagai fasilitas untuk share, } \\
\text { memberikan komentar, membalas } \\
\text { percakapan, tagging, upload foto }\end{array}$ & 62 & $\begin{array}{c}54.9 \\
\%\end{array}$ & 2 & $1.8 \%$ & 21 & $\begin{array}{c}18.6 \\
\%\end{array}$ & 6 & $5.3 \%$ & 15 & $\begin{array}{c}13.3 \\
\%\end{array}$ \\
\hline $\begin{array}{l}\text { Tampilannya nyaman untuk } \\
\text { dilihat dan digunakan }\end{array}$ & 52 & $46 \%$ & 3 & $2.6 \%$ & 23 & $\begin{array}{c}20.4 \\
\%\end{array}$ & 12 & $\begin{array}{c}10.6 \\
\%\end{array}$ & 13 & $\begin{array}{c}11.5 \\
\%\end{array}$ \\
\hline $\begin{array}{l}\text { Semua teman saya } \\
\text { menggunakannya }\end{array}$ & 56 & $\begin{array}{c}49.6 \\
\%\end{array}$ & 1 & $0.8 \%$ & 21 & $\begin{array}{c}18.6 \\
\%\end{array}$ & 7 & $6.2 \%$ & 21 & $\begin{array}{c}18.6 \\
\%\end{array}$ \\
\hline
\end{tabular}

Sumber: Data primer, diolah 2018 
Tabel 3. Frekuensi penerimaan informasi kesehatan pada media sosial

\begin{tabular}{lcc}
\hline \multicolumn{1}{c}{ Penerimaan informasi kesehatan pada media sosial } & Frekuensi $(\boldsymbol{n = 1 1 3})$ & $\mathbf{\%}$ \\
\hline Tidak pernah & 2 & $1.8 \%$ \\
Jarang & 9 & $8 \%$ \\
Cukup sering & 38 & $33.6 \%$ \\
Sering & 44 & $38.9 \%$ \\
Sangat sering & 20 & $17.7 \%$ \\
Total & 113 & $100 \%$ \\
\hline
\end{tabular}

Sumber: Data primer, diolah 2018

Tabel 4. Tindakan setelah mendapatkan informasi kesehatan pada media sosial

\begin{tabular}{|c|c|c|c|c|c|c|c|c|c|c|}
\hline \multirow{2}{*}{$\begin{array}{c}\text { Tindakan setelah } \\
\text { mendapatkan informasi } \\
\text { kesehatan pada media sosial } \\
\text { (Pilihan boleh lebih dari 1, } \\
\text { sehingga prosentase tidak } \\
\text { mecapai 100) }\end{array}$} & \multicolumn{2}{|c|}{$\begin{array}{c}\text { Tidak } \\
\text { Pernah }\end{array}$} & \multicolumn{2}{|c|}{ Jarang } & \multicolumn{2}{|c|}{$\begin{array}{l}\text { Cukup } \\
\text { Sering }\end{array}$} & \multicolumn{2}{|c|}{ Sering } & \multicolumn{2}{|c|}{$\begin{array}{l}\text { Sangat } \\
\text { Sering }\end{array}$} \\
\hline & $\begin{array}{c}\text { Fre- } \\
\text { kuen } \\
- \text { si (n } \\
=113 \\
)\end{array}$ & $\%$ & $\begin{array}{c}\text { Fre- } \\
\text { kuen } \\
\text {-si (n } \\
=113 \\
\text { ) }\end{array}$ & $\%$ & $\begin{array}{c}\text { Fre- } \\
\text { kuen } \\
\text {-si (n } \\
=113 \\
) \\
\end{array}$ & $\%$ & $\begin{array}{c}\text { Fre- } \\
\text { kuen } \\
\text {-si (n } \\
=113 \\
\text { ) }\end{array}$ & $\%$ & $\begin{array}{c}\text { Fre- } \\
\text { kuen } \\
\text {-si (n } \\
=113 \\
)\end{array}$ & $\%$ \\
\hline Memberikan komentar & 28 & $\begin{array}{c}24.8 \\
\%\end{array}$ & 67 & $\begin{array}{c}59.3 \\
\%\end{array}$ & 15 & $\begin{array}{c}13.3 \\
\%\end{array}$ & 0 & 0 & 3 & $2.6 \%$ \\
\hline $\begin{array}{l}\text { Memberikan respon berupa } \\
\text { gambar emoticon/stiker atau } \\
\text { sejenisnya }\end{array}$ & 32 & $\begin{array}{c}28.3 \\
\%\end{array}$ & 50 & $\begin{array}{c}44.2 \\
\%\end{array}$ & 24 & $\begin{array}{c}21.2 \\
\%\end{array}$ & 6 & $5.3 \%$ & 1 & $0.9 \%$ \\
\hline $\begin{array}{l}\text { Meneruskan kembali (share, } \\
\text { forward) }\end{array}$ & 13 & $\begin{array}{c}11.5 \\
\%\end{array}$ & 49 & $\begin{array}{c}43.4 \\
\%\end{array}$ & 40 & $\begin{array}{c}35.4 \\
\%\end{array}$ & 9 & $7.9 \%$ & 2 & $1.8 \%$ \\
\hline $\begin{array}{l}\text { Memberikan tanda "like" atau } \\
\text { sejenisnya yang menyatakan } \\
\text { menyukai informasi yang } \\
\text { disampaikan }\end{array}$ & 9 & $7.9 \%$ & 39 & $\begin{array}{c}34.5 \\
\%\end{array}$ & 43 & $38 \%$ & 15 & $\begin{array}{c}13.3 \\
\%\end{array}$ & 7 & $6.2 \%$ \\
\hline
\end{tabular}

Sumber : Data Primer, diolah 2018 